\title{
Bone density, fractures and the associated factors in iranian children and adolescent with Osteogenesis Imperfecta
}

\author{
Pooran Mohsenzade ${ }^{1}$, Anis Amirhakimi ${ }^{1}$, Naser Honar ${ }^{2}$, Forough Saki ${ }^{3^{*}}$ (D, Gholam Hossein Ranjbar Omrani ${ }^{3}$ (D) and \\ Mohammadhosein Dabbaghmanesh ${ }^{3}$
}

\begin{abstract}
Backround: Osteogenesis imperfecta(OI) is a frequent bone fragility disorder in children. The purpose of this study was to assess the BMD and Vitamin D level in children with Ol in southern Iran.

Method: This case-control study was conducted on 23 children, clinically diagnosed as osteogenesis imperfecta and 23 age- and gender-matched healthy controls. Demographic and anthropometric data, biochemical parameters, puberty, sun exposure and physical activity were assessed. Bone mineral density (BMD) was measured by Dual-energy X-ray absorptiometry (DXA). Data analysis was done by SPSS22.

Results: Forty-three point four percent of Ol patients and fifty-six point five percent of control group had vitamin $D$ deficiency $(P=0.376)$. Thirteen Ol patients $(56 \%)$ had low bone mass for chronological age in lumbar area $(P<$ 0.001). Fracture episodes during treatment was significantly influenced by time of Pamidronate start, courses of Pamidronate injection, puberty and sun exposure ( $P$ values $=0.015,0.030,0.044$ and 0.032 , respectively). Fracture episodes during treatment had significantly increased in patients who had received Pamidronate more than 3 years compared with those received less than 3 years $(P$ values $=0.047$ )

Conclusions: This study showed that vitamin D deficiency is prevalent amongst Ol children in southern Iran. More than half of the Ol children had low bone mass for chronological age in lumbar area, despite receiving bisphosphonate therapy. The present results revealed that early initiation of Pamidronate and number of Pamidronate courses are associated with lower fracture rate. However, treatment period more than 3 years can have adverse effect on fracture rates.
\end{abstract}

Keywords: Children, Osteogenesis Imperfecta, Vitamin D, BMD, Iran

\section{Mini abstract}

This study showed that vitamin-D deficiency is prevalent amongst OI children in southern Iran despite supplemental vitamin-D. $56 \%$ of patients had low bone mass despite receiving bisphosphonate therapy. Early initiation and number of Pamidronate courses are associated with

\footnotetext{
* Correspondence: Sakeif@sums.ac.ir

${ }^{3}$ Shiraz Endocrinology and Metabolism Research Center, Shiraz University of Medical Sciences, P.O. Box: 71345-1744, Shiraz, Iran

Full list of author information is available at the end of the article
}

lower fracture rate. Treatment longer than 3 years can aggravate fractures.

\section{Background}

Osteogenesis imperfecta(OI), or brittle bone disease, is one of the most common primary bone fragility disorder in children and adolescents. It is due to a mutation in one of the two genes coding for collagen type I, the genes associated with the modification of collagen type 1 and some transcription factors are related with

(c) The Author(s). 2021 Open Access This article is licensed under a Creative Commons Attribution 4.0 International License, which permits use, sharing, adaptation, distribution and reproduction in any medium or format, as long as you give appropriate credit to the original author(s) and the source, provide a link to the Creative Commons licence, and indicate if changes were made. The images or other third party material in this article are included in the article's Creative Commons licence, unless indicated otherwise in a credit line to the material. If material is not included in the article's Creative Commons licence and your intended use is not permitted by statutory regulation or exceeds the permitted use, you will need to obtain permission directly from the copyright holder. To view a copy of this licence, visit http://creativecommons.org/licenses/by/4.0/ The Creative Commons Public Domain Dedication waiver (http://creativecommons.org/publicdomain/zero/1.0/) applies to the data made available in this article, unless otherwise stated in a credit line to the data. 
osteoblast differentiation $[1,2]$. Its prevalence was reported as 1 in 15-20,000 births [1]. Diagnosis is based on history, clinical findings and radiographic findings of repeated old and new fractures which showed no criteria of other metabolic bone disease. Radiographs was used to ruled out other metabolic bone disease such as rickets. Its clinical manifestations are classified as skeletal and extra-skeletal. Skeletal features include bowing deformities of long bones, macrocephaly, fracture due to mild trauma, face malformation, chest wall deformities and short stature. Extra-skeletal manifestations consist in blue sclera, dentinogenesis imperfecta, and hearing impairment [2, 3]. OI has been categorized, according to clinical presentation into four types(types I- IV), based on Sillence criteria [4]. This criteria was introduced in 1979 according to clinical and radiological findings and mode of inheritance, prior to the availability of molecular genetic analyses. Type I is mild and the most frequent type without bone deformity and short stature. it's inheritance is autosomal-dominant and these patients may have blue sclera. OI type II is the pre- or perinatal lethal form because of multiple fractures, osteopenia and pulmonary hypoplasia. OI type III is the most severe type in children surviving the neonatal period, suffer several peripheral and vertebral fractures. At last, OI type IV is an overlapping phenotype of OI types I and III with variable clinical presentation. Clinical OI types II, III, and IV have either autosomal or recessive inheritance.

Unfortunately, treatment of OI patients is limited to supportive care and there is no cure for them. According to the disease severity, degree of impairment and age of the individual, mode of therapy is varied and individualized. These therapies include orthopedic management e.g. surgical intervention or bracing of lower limbs, physical and occupational therapy, and drugs including bisphosphonates, growth hormone, calcitonin, parathyroid hormone, sodium fluoride, vitamins. Bisphosphonates are currently the most useful pharmacologic therapy. Nearly all the previous reports evaluating BMD in patients with osteogenesis imperfecta independently reported a significant increase in BMD after treatment with either oral or IV. However, it is difficult to compare the results of these trials because they had studied different populations (adults versus children; because children cannot be compared with adults due to high bone turnover during growth years with open epiphyses). Moreover, although OI patients are taking Bisphosphonates like Pamidronate to increase bone density and reduce fractures [5], the patients suffer primary osteoporosis, most observed in lumbar area due to intrinsic bone disease $[6,7]$. Studies from around the globe showed different prevalence rates of osteopenia in patients with OI; hence, it is important to evaluate bone density and fracture risk in OI patients to prevent future fractures and disabilities and improve their quality of life. Also, understanding the prevalence of osteoporosis and its related factors in children with OI can help the pediatricians to do a more accurate management of OI patients [8-10].

In addition, vitamin $\mathrm{D}$ plays an essential role in obtaining adequate bone mineralization, and also has a positive effect on muscles, which can indirectly have a favorable influence on bone [6]. Low levels of serum 25-hydroxyvitamin $\mathrm{D}(25 \mathrm{OHD})$ in many children and adolescents with OI has been shown in prior studies $[6,9,11,12]$.

The purpose of this study was to evaluate Vitamin D deficiency, bone mineral density, fracture rate and its associated factors amongst children and adolescents with Osteogenesis Imperfecta in a case-control study in southern Iran.

\section{Methods \\ Study design}

This study case was conducted on 23 patients in Shiraz, a city in southern Iran, clinically diagnosed as Osteogenesis Imperfecta who were referred to the pediatric endocrinology ward of Namazi hospital affiliated with Shiraz University of Medical Sciences (SUMS), for receiving intravenous Pamidronate, during spring and summer of 2018. Inclusion criteria were clinical diagnosis of OI type I, III, or IV which had diagnosed and followed in pediatric endocrinology clinic and age of 1-18 years. Exclusion criteria were secondary causes of osteoporosis including any systemic inflammatory or autoimmune disease, liver or kidney disease, diabetes mellitus, and any medical history of malignancy. Demographic data and detailed medical history (fracture rate, time of the first fracture, history of intrauterine fracture and treatment period) was obtained from each patient. At the time of admission, all patients were taking supplemental calcium and vitamin D (500 mg calcium carbonate and 200 IU vitamin D per day). Twenty-three healthy ageand gender-matched children were recruited from the local schools in Shiraz through an age/gender-stratified randomly selected sampling method as the control group.

\section{Body size, pubertal status, physical activity and sun exposure}

A trained physician measured weight, height or length and pubertal stage of the participants. The height was recorded, using a standard wall-mounted meter [13], while the children were standing without shoes and it was rounded to the nearest $0.5 \mathrm{~cm}$. Infants and children unable to stand were measured in the supine position. Weight was measured with a standard scale (Seca, 
Germany) while the children wore a light clothes without shoes and it was rounded to the nearest $0.1 \mathrm{~kg}$. Body mass index (BMI) was calculated using the standard formula:

$$
\text { BMI }(\mathrm{kg} / \mathrm{m} 2)=\text { weight }(\mathrm{kg}) /[\text { height }(\mathrm{m})] 2
$$

BMI was converted to age- and gender-specific percentile according to reference data published by the Centers for Disease Control and Prevention [14].

Evaluation of puberty was assessed through the Tanner standard staging system by examination of a pediatric endocrinologist [15]. Participants were categorized as pre pubertal (Tanner 1), early pubertal (Tanner 2 and 3), and late pubertal (Tanner 4 and 5). According to the last recommendation of the American College of Sports Medicine, physical activity was classified into sufficient (3 days of physical activity per week) and insufficient groups (less than 3 days per week) [16]. It includes walking, riding bicycle, playing aerobic exercise such as football. Furthermore, we categorized the patients based on their subjective report of daily sun exposure (during 10 a.m. - 4 p.m.) into three groups: (1) low exposure, less than $15 \mathrm{~min} /$ day; (2) medium exposure,15-30 $\mathrm{min} /$ day; and (3) high exposure, more than $30 \mathrm{~min}$ sun exposure daily [17].

\section{Biochemical parameters}

All the blood samples were taken by an expert technician after 8-12 h of fasting (before starting Pamidronate) and assessed in Shiraz Endocrinology and Metabolism Research Center. Serum calcium (Ca), Phosphorous (P), and Alkaline phosphatase (ALP) were checked using colorimetric assay with an auto analyzer (Bio system SA, Barcelona, Spain). Serum concentration of 25-hydroxy vitamin $\mathrm{D}(25 \mathrm{OHD})$ was assessed with a high performance liquid chromatography (Young Lee 9100, South Korea) in $\mathrm{ng} / \mathrm{ml}$. The intra-and inter-assay coefficients of variation were 8.2 and $8.4 \%$, respectively. Based on the last guideline published by the Endocrine Society for Clinical Practice, serum concentration of 25OHD less than $20 \mathrm{ng} / \mathrm{ml}$ was defined as vitamin D deficiency [15].

\section{Bone mineral density}

Bone mineral density measurement of individuals was done by Hologic system DXA (Discovery QDR, USA). The standard data of Hologic system DXA (Discovery QDR, USA) which was from the U.S. Centers for Disease Control's National Health and Nutrition Examination Survey (NHANES) accounted for interpreting healthy children [15]. In our center, according to the measurements in 10 children, the coefficient of variation was $0.48 \%$ for the lumbar spine. BMD $(\mathrm{g} / \mathrm{cm} 2)$ Z-score less than - 2 for patient's age and gender was considered as low bone mass for chronological age (LBM).

In growing children, the most important problem in the interpretation of BMD is the effect of bone size on bone mineral content (BMC) and BMD. It means that larger bones due to their greater thickness might have a higher areal BMD. The best solution for this problem is to calculate the bone density per unit volume [17]. To reach this goal, we used bone mineral apparent density (BMAD) to evaluate the child bone density in our study. Estimated volumetric BMAD was calculated for the lumbar spine, using the following formula:

$$
\text { Lumbar BMAD = BMC of L2 - L4/(area) } 1.5
$$

\section{Statistical analysis}

SPSS software version 22 reference [18] was used for Data analysis. Descriptive data are presented as mean \pm standard deviation and percentages. Qualitative variables were compared by Chi-square test and Fisher exact test between the case and control groups. KolmogorovSmirnov test was used to evaluate the normality of data distribution. Students t-test and Mann-Whitney test were used to compare quantitative variables between two groups. Multiple linear regression model was used to determine independent factors influencing DXA indices. $P$ value less than 0.05 was considered to be statistically significant.

\section{Results}

The present study assessed 23 OI patient with an average age of $8.29 \pm 4$ years and 23 healthy age- and gender-matched children ( 9 males and 14 females). In OI patients, $60.9 \%$ had family history of fracture, $69.6 \%$ history of parental consanguinity and $13 \%$ had intrauterine fractures. All of the OI children had previous fractures, and 6 had blue sclera. Among all the patients, 6(26\%) had type 1 and 17(64\%) had type 4 Osteogenesis Imperfecta. In total, $17.4 \%$ has taken Pamidronate for more than 3 years and $82.6 \%$ less than 3 years.

Table 1 shows the general characteristics of the case and control population. The variables were not normal based on One-Sample Kolmogorov-Smirnov Test $(P<$ $0.05)$, so Mann-Whitney test was used for comparison. Vitamin D level was higher in OI $(25.80 \pm 15.34)$ than the control group $(18.35 \pm 5.35)$ with $P$ value of 0.033 . Physical activity was also different between cases and control group $(P<0.001)$. There was no statistically significant difference in other variables, such as age $(y)$, calcium (mg/dl), phosphorous ( $\mathrm{mg} / \mathrm{dl})$, alkaline phosphates (IU/L), height, weight, BMI, sun exposure, and puberty between the two groups. 
Table 1 General characteristics of patients and control group and the related comparisons

\begin{tabular}{|c|c|c|c|}
\hline variable & Control group & OI children & $P$-value \\
\hline Age (y) & $8.29 \pm 4$ & $8.29 \pm 4$ & 1 \\
\hline Calcium (mg/dl) & $9.85 \pm 0.49$ & $9.64 \pm 0.67$ & 0.230 \\
\hline Phosphorous (mg/dl) & $4.42 \pm 0.5$ & $4.80 \pm 0.83$ & 0.063 \\
\hline Alkaline phosphates (IU/L) & $428 \pm 74$ & $534 \pm 250$ & 0.063 \\
\hline $25 \mathrm{OHD}(\mathrm{ng} / \mathrm{ml})$ & $18.35 \pm 5.35$ & $25.80 \pm 15.34$ & 0.033 \\
\hline Height & $124.96 \pm 22.10$ & $119 \pm 25.10$ & 0.398 \\
\hline Weight & $24.43 \pm 9.50$ & $24.04 \pm 13.20$ & 0.909 \\
\hline BMI & $15.24 \pm 2.27$ & $15.73 \pm 3.50$ & 0.580 \\
\hline BMI Percentile & $28.91 \pm 6.92$ & $36.52 \pm 6.20$ & 0.418 \\
\hline \multirow[t]{3}{*}{ Sun exposure (\%) } & Low 52\% & Low 61\% & 0.329 \\
\hline & Medium 43\% & Medium 26\% & \\
\hline & High 5\% & High 13\% & \\
\hline \multirow[t]{2}{*}{ Physical activity (\%) } & Insufficient 21.7\% & Insufficient 73.9\% & $<0.001$ \\
\hline & Sufficient $78.3 \%$ & Sufficient $26.1 \%$ & \\
\hline \multirow[t]{3}{*}{ Puberty (\%) } & Pre pubertal $78 \%$ & Pre pubertal $61 \%$ & 0.359 \\
\hline & Early pubertal 13\% & Early pubertal 30\% & \\
\hline & Late pubertal 9\% & Late pubertal 9\% & \\
\hline \multirow[t]{2}{*}{ Sex (\%) } & Male $39.1 \%$ & Male $39.1 \%$ & 0.618 \\
\hline & Female $60.9 \%$ & Female 60.9\% & \\
\hline
\end{tabular}

About $43 \%$ of OI patients and $56 \%$ of the control group had vitamin $\mathrm{D}$ deficiency, which was not significantly different between patients and controls $(P=0.376)$, Fig. 1 . Regression analysis of the associated factors with vitamin $\mathrm{D}$ level revealed that none of the below factors, such as age, gender, BMI percentile, sun exposure, puberty, physical activity, intrauterine fracture, courses of Pamidronate injection, Fracture episodes during treatment, Lumbar BMAD and Lumbar z-score can be a predictor of vitamin $\mathrm{D}$ level in OI patients (Table 2).

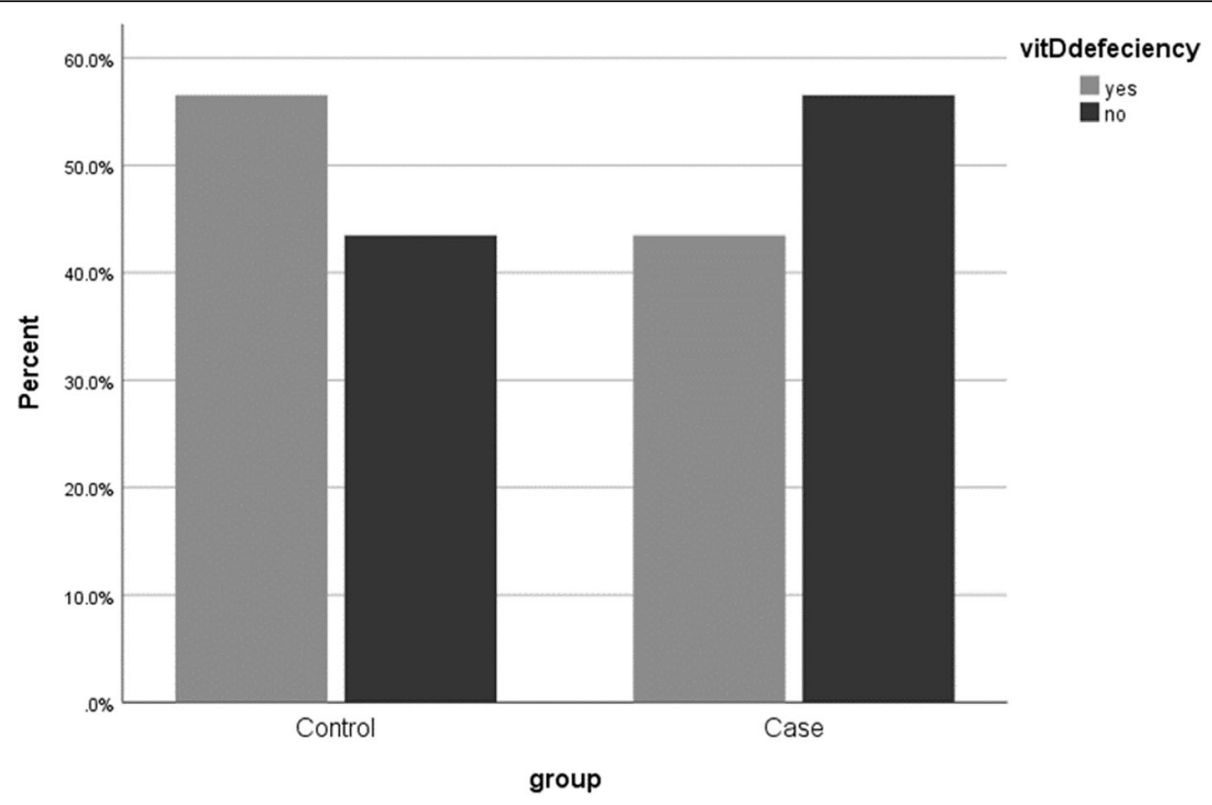

Fig. 1 Prevalence of vitamin D defeciency in Ol and control group $(P=0.376)$ 
Table 2 Results of multiple linear regressions of associated factors with vitamin D level conducted by Enter method

\begin{tabular}{lll}
\hline variables & Beta & p-value \\
\hline age & -0.145 & 0.803 \\
gender & -0.439 & 0.117 \\
BMI percentile & 0.347 & 0.291 \\
Puberty & 0.870 & 0.240 \\
Physical activity & 0.495 & 0.147 \\
Sun exposure & -0.852 & 0820. \\
Intra uterine fracture & 0.087 & 0.739 \\
courses of Pamidronate injection & -0.575 & 0.056 \\
fracture episodes during treatment & -0.198 & 0.595 \\
Lumbar BMAD & -0.859 & 0.108 \\
Lumbar z-score & 0.820 & 0.139 \\
\hline
\end{tabular}

None of the participants in the control group (0\%), but 13 cases in OI (56\%) had low bone mass for chronological age in lumbar area $(P<0.001)$. Lumbar BMD, $\mathrm{BMC}, \mathrm{BMAD}$ and Z-score were significantly lower in OI ( $P$ values $=0.002,0.000,0.002$ and 0.001 , respectively $)$. Details of DXA indices of lumbar area in both case and control groups are shown in Table 3. The variables were normal based on One-Sample Kolmogorov-Smirnov Test $(P>0.05)$, so Students t-test were used for comparison However, there were no differences between lumbar low bone mass and variables like: Vitamin D, age, Calcium (mg/dl), Phosphorous (mg/dl), Alkaline phosphates (IU/L), BMI percentile, gender, sun exposure, puberty, physical activity, vitamin $\mathrm{D}$ deficiency, intrauterine fracture and fracture episodes during treatment.

To evaluate the association between fracture episodes and the possible associated factors such as BMI percentile, intra uterine fracture, Pamidronate therapy initiation time, number of Pamidronate injections, total time of Pamidronate therapy, puberty, vitamin D, age, gender, physical activity, sun exposure, and Lumbar BMAD, multiple linear regression model by Enter method was used.(R Square: 0.914).

Puberty and sun exposure was revalued into 2 groups. Puberty; group1: early puberty and late puberty, group 2 : pre puberty. Sun exposure group1: less than $15 \mathrm{~min} /$ day and 15-30 $\mathrm{min} /$ day, group 2: more than $30 \mathrm{~min}$.
Fracture episodes during treatment was significantly associated with the age, gender, initiation time of Pamidronate therapy, number of Pamidronate injection, puberty and sun exposure $(P$ values $=0.003,0.015,0.000$, $0.002,0.005$ and 0.006 , respectively). Table 4 shows the association between fracture episodes during treatment and some possible associated factors in OI children. In addition, it was shown that number of fracture episodes had raised in patients who had received Pamidronate for more than 3 years compared with those received below 3 years $(P$ values $=0.047)$.

\section{Discussion}

The present study showed that children with Osteogenesis Imperfecta had higher mean vitamin D level than the healthy control group, which might have been due to supplementary calcium and vitamin D consumption. In spite of having higher vitamin $\mathrm{D}$ levels found in patients with OI, $43.4 \%$ of them had criteria of vitamin D deficiency, which can reflect upon supplementary vitamin D dosage insufficiency, poor compliance or secondary causes. We showed that $56.5 \%$ of the control group had vitamin D deficiency. A previous study in south of Iran showed that $81.3 \%$ of healthy children had vitamin $\mathrm{D}$ deficiency, which was due to insufficient sun exposure, inadequate physical activity, pubertal stage and advancing age [16]. To the best of our knowledge, our study is amongst the few that reported the prevalence of vitamin $\mathrm{D}$ deficiency in OI pediatric patients in the Middle East. Most of the previous studies that had assessed vitamin D level in OI patients, were from North America [6, 9, 11, 12, 19] and Brazil [20]. The present study was similar to a report from Edouard et al. in 2011 which showed that $52 \%$ of 71 OI patients in Montreal Canada had vitamin D deficiency [19]. In addition, Zambrano et al. in 2016 revealed that $35.5 \%$ and $51.9 \%$ of 52 Brazilian OI children had vitamin D deficiency and insufficiency, respectively [20]. In line with our findings, Edouard et al. in 2011 reported that there was no association between 25OHD level with measures of bone mineralization in OI children [19]. There are considerable evidences that vitamin $\mathrm{D}$ deficiency raises the risk of falls and fractures [15]. Consequently, regular evaluation of vitamin D deficiency and if so, its treatment has

Table 3 DXA characteristics of lumbar area in both case and control groups

\begin{tabular}{lllll}
\hline variable & $\begin{array}{l}\text { Control group } \\
\boldsymbol{N}=\mathbf{2 3} \\
\text { Mean } \pm \text { SD }\end{array}$ & $\begin{array}{l}\text { Ol children } \\
\boldsymbol{N}=\mathbf{2 3} \\
\text { Mean } \pm \text { SD }\end{array}$ & P-value \\
\hline Lumbar BMD (g/cm2) & $0.60 \pm 0.15$ & $0.47 \pm 0.10$ & 0.002 & 3.00 \\
Lumbar BMC (g) & $25.35 \pm 10.74$ & $14.76 \pm 5.30$ & 0.000 & 4.00 \\
Lumbar BMAD (g/cm3) & $0.40 \pm 0.10$ & $0.31 \pm 0.07$ & 0.002 & 1.00 \\
Lumbar BMD Z-score & $-0.53 \pm 0.75$ & $-2.27 \pm 2.17$ & 0.001 & 3.00 \\
\hline
\end{tabular}


Table 4 Results of multiple linear regressions of associated factors with fracture episodes during treatment conducted by Enter method. R Square: 0.914

\begin{tabular}{llll}
\hline variables & Std.Error & Beta & $\boldsymbol{p}$-value \\
\hline age & 0.197 & 1.314 & $\mathbf{0 . 0 0 3}$ \\
gender & 0.572 & -0.349 & $\mathbf{0 . 0 1 5}$ \\
BMl percentile & 0.010 & -0.075 & 0.548 \\
Puberty & 1.128 & 0.850 & $\mathbf{0 . 0 0 5}$ \\
Physical activity & 0.683 & 0.113 & 0.402 \\
Sun exposure & 0.760 & -0.549 & $\mathbf{0 . 0 0 6}$ \\
Vitamin D & 0.020 & -0.108 & 0.421 \\
Intra uterine fracture & 0.837 & -0.266 & 0.053 \\
Pamidronate therapy initiation time & 0.249 & -2.462 & $\mathbf{0 . 0 0 0}$ \\
Number of Pamidronate injection & 0.058 & -0.878 & $\mathbf{0 . 0 0 2}$ \\
Total time of Pamidronate therapy & 0.264 & -0.603 & 0.100 \\
Lumbar BMAD & 14.062 & -0.075 & 0.511 \\
\hline
\end{tabular}

great benefit in OI patients who suffer from frequent disabling fractures.

Most of children with OI, show short stature with small body size for age as a result of growth retardation. Hence, we used volumetric BMD or BMAD for a more accurate interpretation of BMD results, due to the effect of body size on BMD [17]. BMD parameters like Lumbar $\mathrm{BMD}, \mathrm{BMAD}$ and Z-score were very low in our cases in comparison with control group, which was anticipated in a population with OI. There was no significant association between Lumbar BMAD and Z-score and vitamin $\mathrm{D}$ level, which is reflection of BMD parameters of OI patients that varies in the severity of disease. Bisphosphonate treatment is established as a standard treatment for moderate to severe cases, who suffer from bone fractures. Bisphosphonates not only increase lumbar spine (LS) BMD but also improve bone structures, increase mobility and reduce fracture risk [4, 6]. In 2019 Bains et al. in a cohort multicenter study on 299 individuals with OI type I (a mild form of disease), revealed that people who were receiving bisphosphonates, BMD and mobility had increased, fracture rate and scoliosis was decreased in comparison with the group who did not took bisphosphonates [21]. There is no unanimous view as to when bisphosphonate treatment should be initiated for individuals with OI [4]. Our results provide evidence that time of treatment initiation and courses of Pamidronate injection is linked with fracture rates, which means that early start of treatment and regular intervals might reduce fracture rates. In 2008, Poyrazoglu et al. revealed that younger children with OI responded faster to Pamidronate treatment by increase in their BMD Z-score [8]. Fracture rates was in correlation with puberty and sun exposure. Another finding of our study was that Pamidronate therapy duration of more than 3 years (long term treatment) increased fracture rate without any change in BMD parameters, which might lead to bone fragility. In contrast, one study on 79 Swedish children reported that after more than 4 years of Pamidronate treatment, fracture rate was reduced [4].

Our study has several strengths. It is amongst limited case-control studies, assessing vitamin D status, BMD and its associated factors in children with $\mathrm{OI}$ as a rare disease in the Middle East. Also, we used volumetric $\mathrm{BMD}$ (BMAD) in OI children to reduce the effect of bone size on BMC and BMD, even though there are limited reports. Despite these strengths, we had several limitations. Although we used a standard questionnaire, physical activity, sun exposure and fracture data were self-reported and underwent recall bias. Second, all the patients had received vitamin $D$ supplements since the time of diagnosis, so we could not evaluate the true prevalence of vitamin D deficiency, however, they had vitamin $\mathrm{D}$ deficiency in spite of receiving supplements. Last but not the least, was our mandatory small sample size, which could have influenced the results e.g. regression analysis. Multicenter studies are warranted to find all the correlates.

\section{Conclusions}

This study showed that $43.4 \%$ of OI children in southern Iran had vitamin D deficiency. There was no association between Vitamin D level and BMD parameters. In total, $56 \%$ of OI children had low bone mass for chronological age in lumbar area. Our results provide evidence that early initiation of Pamidronate therapy and courses of Pamidronate injections led to reduction in fracture rates. However, treatment period of more than 3 years had adverse effect on fracture rates. Performing DXA before treatment and monitoring it during treatment is recommended in children with OI.

\section{Abbreviations}

25OHD: 25-hydroxyvitamin D; ALP: Alkaline phosphatase; BMI: Body mass index; BMD: Bone mineral density; BMAD: bone mineral apparent density; Ca: Calcium; DXA: Dual-energy X-ray absorptiometry; LBM: low bone mass for chronological age; NHANES: National Health and Nutrition Examination Survey; OI: Osteogenesis imperfecta; P: Phosphorous; SUMS: Shiraz University of Medical Sciences; SPSS: SPSS statistical software

\section{Acknowledgements}

The authors wish to thank Mr. H. Argasi at the Research Consultation Center (RCC) of Shiraz University of Medical Sciences for his invaluable assistance in editing this manuscript.

\section{Disclosure summary}

Pooran Mohsenzade, Anis Amirhakimi, Naser Honar, Forough Saki, Gholamhossein Ranjbar Omrani and Mohammadhosein Dabbaghmanesh have nothing to declare.

\section{Authors' contributions}

PM, contributed in design, data gathering, preparing the manuscript. AA, contributed in design, data gathering, preparing the manuscript. $\mathrm{NH}$, 
contributed in design, data gathering, preparing the manuscript. FS*, contributed in concept, design, data gathering, data analysis, preparing the manuscript and the correspondence. GHRO, contributed in data gathering of control patients, design. MD, contributed in data gathering of control patients, design. All authors have read and approved the manuscript

\section{Funding}

There is no financial support.

\section{Availability of data and materials}

The datasets used and/or analyzed during the current study are available from the corresponding author on reasonable request.

\section{Ethics approval and consent to participate}

The local Ethics Committee and Vice-Chancellor of research at Shiraz University of Medical Sciences(SUMS) approved this study with number 95-01-0113972. All the patients and their parents signed a written informed consent form for participation in the study and any possible publication of their data, after explaining the aim, method and goal of the study for the participants.

\section{Consent for publication}

All the patients signed a written informed consent form for publication of any data from their results after a session of explaining the aim, method, and goal of the study for each participant.

\section{Competing interests}

Pooran Mohsenzade, Anis Amirhakimi, Naser Honar, Forough Saki, Gholamhossein Ranjbar Omrani and Mohammadhosein Dabbaghmanesh declare that they have no conflict of interest.

\section{Author details}

${ }^{1}$ Shiraz University of Medical Sciences, Shiraz, Iran. ${ }^{2}$ Gastroentrology Research Center, Neonatology Research Center, Shiraz University of Medical Sciences, Shiraz, Iran. ${ }^{3}$ Shiraz Endocrinology and Metabolism Research Center, Shiraz University of Medical Sciences, P.O. Box: 71345-1744, Shiraz, Iran.

Received: 26 May 2020 Accepted: 29 December 2020 Published online: 14 January 2021

\section{References}

1. Bregou Bourgeois A, Aubry-Rozier B, Bonafé L, Laurent-Applegate LA, Pioletti D, Zambelli P-Y. Osteogenesis imperfecta: from diagnosis and multidisciplinary treatment to future perspectives. Swiss Med Wkly. 2016; 146(ARTICLE):w14322.

2. Forlino A, Marini JC. Osteogenesis imperfecta. Lancet. 2016;387(10028): 1657-71.

3. Kocijan R, Muschitz C, Haschka J, Hans D, Nia A, Geroldinger A, et al. Bone structure assessed by HR-pQCT, TBS and DXL in adult patients with different types of osteogenesis imperfecta. Osteoporos Int. 2015;26(10):2431-40.

4. Lindahl K, Kindmark A, Rubin C-J, Malmgren B, Grigelioniene G, Söderhäll S, et al. Decreased fracture rate, pharmacogenetics and BMD response in 79 Swedish children with osteogenesis imperfecta types I, III and IV treated with Pamidronate. Bone. 2016:87:11-8.

5. Dwan K, Phillipi CA, Steiner RD, Basel D. Bisphosphonate therapy for osteogenesis imperfecta. Cochrane Database Syst Rev. 2016(10).

6. Plante L, Veilleux L-N, Glorieux FH, Weiler H, Rauch F. Effect of high-dose vitamin D supplementation on bone density in youth with osteogenesis imperfecta: a randomized controlled trial. Bone. 2016:86:36-42.

7. Bratanic N, Dzodan B, Podkrajsek KT, Bertok S, Ostanek B, Marc J, et al. Childhood Osteoporosis and Presentation of Two Cases with Osteogenesis Imperfecta Type V/Osteoporoza V Otroški Dobi in Predstavitev Dveh Bolnikov Z Osteogenesis Imperfecta Tipa V. Slovenian J Public Health. 2015; 54(2):119-25.

8. Poyrazoglu S, Gunoz H, Darendeliler F, Bas F, Tutunculer F, Eryilmaz SK, et al. Successful results of pamidronate treatment in children with osteogenesis imperfecta with emphasis on the interpretation of bone mineral density for local standards. J Pediatr Orthop. 2008;28(4):483-7.

9. Edouard T, Glorieux FH, Rauch F. Predictors and correlates of vitamin D status in children and adolescents with osteogenesis imperfecta. J Clin Endocrinol Metab. 2011;96(10):3193-8.
10. Kok DH, Sakkers RJ, Pruijs HE, Joosse P, Castelein RM. Bone mineral density in developing children with osteogenesis imperfecta: a longitudinal study with 9 years of follow-up. Acta Orthop. 2013;84(4):431-6.

11. Wilsford LD, Sullivan E, Mazur LJ. Risk factors for vitamin D deficiency in children with osteogenesis imperfecta. J Pediatr Orthop. 2013;33(5):575-9.

12. Bowden SA, Robinson RF, Carr R, Mahan JD. Prevalence of vitamin D deficiency and insufficiency in children with osteopenia or osteoporosis referred to a pediatric metabolic bone clinic. Pediatrics. 2008;121(6): e1585-e90.

13. Renstrom SB, Andersen CS, Pedersen CH, Madsen FF. Correct measurement of height is important when assessing lung function values. Dan Med J. 2012:59(2):A4376.

14. Edouard T, Husseini A, Glorieux FH, Rauch F. Serum 24,25-dihydroxyvitamin $D$ concentrations in osteogenesis imperfecta: relationship to bone parameters. J Clin Endocrinol Metab. 2012:97(4):1243-9.

15. Bordbar MR, Haghpanah S, Dabbaghmanesh MH, Omrani GR, Saki F. Bone mineral density in children with acute leukemia and its associated factors in Iran: a case-control study. Arch Osteoporosis. 2016;11(1):36.

16. Saki F, Dabbaghmanesh MH, Omrani GR, Bakhshayeshkaram M. Vitamin D deficiency and its associated risk factors in children and adolescents in southern Iran. Public Health Nutr. 2017;20(10):1851-6.

17. Saki F, Haghpanah S, Zarei T, Dabbaghmanesh MH, Omrani GR, Bordbar M. Investigating the bone mineral density in children with solid tumors in southern Iran: a case-control study. Arch Osteoporosis. 2018:13(1):8.

18. Gouda MA. Common Pitfalls in Reporting the Use of SPSS Software. Med Princ Pract. 2015:24(3):300

19. Edouard T, Glorieux FH, Rauch F. Relationship between vitamin D status and bone mineralization, mass, and metabolism in children with osteogenesis imperfecta: histomorphometric study. J Bone Miner Res. 2011;26(9):2245-51.

20. Zambrano MB, Brizola E, Pinheiro B, Vanz AP, Mello ED, Félix TM. Study of the determinants of vitamin $D$ status in pediatric patients with osteogenesis imperfecta. J Am Coll Nutr. 2016;35(4):339-45.

21. Bains JS, Carter EM, Citron KP, Boskey AL, Shapiro JR, Steiner RD, et al. A Multicenter Observational Cohort Study to Evaluate the Effects of Bisphosphonate Exposure on Bone Mineral Density and Other Health Outcomes in Osteogenesis Imperfecta. JBMR Plus. 2019;3(5):e10118.

\section{Publisher's Note}

Springer Nature remains neutral with regard to jurisdictional claims in published maps and institutional affiliations.

Ready to submit your research? Choose BMC and benefit from:

- fast, convenient online submission

- thorough peer review by experienced researchers in your field

- rapid publication on acceptance

- support for research data, including large and complex data types

- gold Open Access which fosters wider collaboration and increased citations

- maximum visibility for your research: over $100 \mathrm{M}$ website views per year

At $\mathrm{BMC}$, research is always in progress.

Learn more biomedcentral.com/submissions 